\title{
Evaluation of leptin levels among fibromyalgia patients before and after three months of treatment, in comparison with healthy controls
}

\author{
Jacob N Ablin MD ${ }^{1}$, Natalia Aronov MD², Ilan Shimon MD³, Hannah Kanety $\mathrm{PhD}^{4}$, Clara Pariente $\mathrm{MSc}^{4}$, \\ Valerie Aloush $\mathrm{MD}^{1}$, Ori Elkayam $\mathrm{MD}^{1}$, David Levartovsky $\mathrm{MD}^{1}$
}

JN Ablin, N Aronov, I Shimon, et al. Evaluation of leptin levels among fibromyalgia patients before and after three months of treatment, in comparison with healthy controls Pain Res Manage 2012;17(2):89-92.

BACKGROUND: Leptin, an adipocyte-produced cytokine, interacts with various hormones, including those of the hypothalamic-pituitaryadrenal axis. Fibromyalgia is a syndrome characterized by widespread pain accompanied by tenderness. The pathogenesis involves a disturbance in pain processing and transmission by the central nervous system, leading to a general increase in pain perception.

OBJECTIVES: To analyze potential changes in leptin levels among female fibromyalgia patients compared with healthy controls, and to evaluate the changes in leptin levels during treatment.

METHODS: Sixteen female fibromyalgia patients were recruited. Patients underwent clinical evaluation, physical examination, including manual dolorimetry, and were evaluated regarding quality of life, pain, fatigue, anxiety and depression. Plasma leptin levels were determined by ELISA. Patients were offered standard treatment for fibromyalgia. Clinical evaluation and leptin determination were repeated after three months.

RESULTS: No significant difference was observed between leptin levels among fibromyalgia patients and controls; no significant correlation was observed between leptin levels and clinical parameters reflecting fibromyalgia severity; and no significant change was observed in leptin levels over three months of treatment. These results did not change after adjustment of leptin levels for body mass index values.

CONCLUSIONS: The results of the present study do not support the existence of a significant relationship between leptin and fibromyalgia pathogenesis. Increasing the sample size or examining the interaction between leptin and additional hormones/mediators of metabolism and body weight control may yet uncover significant information in this field.

Key Words: Chronic pain; Fibromyalgia; Leptin

Cibromyalgia is a syndrome involving alteration of central pain processing and is clinically characterized by the presence of widespread pain and tenderness. The syndrome, which is considered to represent a disorder of central pain processing (1), is believed to involve alterations in the central nervous system levels of various neurotransmitters participating in the transmission of pain including (but not limited to) noradrenaline, serotonin and substance $\mathrm{P}(2)$. Stress is an important trigger for fibromyalgia and alterations of the hypothalamic-pituitaryadrenal (HPA) axis are described (3). Other studies have pointed toward alterations of the growth hormone axis in fibromyalgia (4), while depression - a condition classically considered to involve a reduction in central nervous system serotonin levels - is a frequent comorbidity (5).

Originally considered to be a mediator of satiety, leptin - the product of the $o b / o b$ gene - is an adipocyte-derived hormone involved in energy expenditure and regulation (6).

\author{
L'évaluation des taux de leptine chez des patientes \\ atteints de fibromyalgie avant et après un \\ traitement de trois mois, par rapport à des sujets \\ témoins en bonne santé
}

\begin{abstract}
HISTORIQUE : La leptine, une cytokine issue de l'adipocyte, interagit avec diverses hormones, y compris celles de l'axe hypothalamique-pituitaire-adrénal. La fibromyalgie est un syndrome caractérisé par une douleur généralisée accompagnée d'une sensibilité. La pathogenèse inclut une perturbation du traitement et de la transmission de la douleur par le système nerveux central, qui suscite une augmentation générale de la perception de la douleur.

OBJECTIFS : Analyser les changements potentiels aux taux de leptine chez les patientes ayant une fibromyalgie par rapport à des sujets témoins en bonne santé et évaluer les changements aux taux de leptine pendant le traitement. MÉTHODOLOGIE : Seize patientes ayant une fibromyalgie ont été recrutées. Elles ont subi une évaluation clinique, un examen physique, y compris une dolorimétrie manuelle, ainsi qu'une évaluation de leur qualité de vie, de leur douleur, de leur fatigue, de leur anxiété et de leur dépression. On a déterminé leurs taux plasmatiques de leptine par ELISA et on leur a offert le traitement habituel de la fibromyalgie. On a répété l'évaluation clinique et la détermination de la leptine au bout de trois mois.

RÉSULTATS : Les auteurs n'ont observé aucune différence considérable entre les taux de leptine chez les patientes ayant une fibromyalgie et les sujets témoins. Ils n'ont observé aucune corrélation significative entre les taux de leptine et les paramètres cliniques reflétant la gravité de la fibromyalgie et aucun changement significatif des taux de leptine pendant les trois mois de traitement. Les résultats n'ont pas changé après rajustement des taux de leptine selon les valeurs d'indice de masse corporelle.

CONCLUSIONS : Les résultats de la présente étude n'appuient pas l'existence d'un lien important entre la leptine et la pathogenèse de la fibromyalgie. Si on augmentait la dimension de l'échantillon ou qu'on examinait l'interaction entre la leptine, d'autres hormones ou médiateurs du métabolisme et le contrôle du poids, on pourrait peut-être découvrir de l'information importante dans ce domaine.
\end{abstract}

Leptin levels are higher in women compared with men (7), and secretion is characterized by a diurnal variation, with maximal levels observed during the night (8). In animal models, leptin has been shown to inhibit the response of the HPA axis to stress by inhibiting the secretion of cortisol-releasing hormone (9). A complex interaction between leptin and the HPA is demonstrated by the finding of decreased leptin levels together with HPA activation during surgical stress (10). Moreover, while leptin inhibits the HPA, it is itself stimulated by glucocorticoids, endotoxins and cytokines (11). Depression and schizophrenia have both been associated with decreased leptin levels (12), while treatment with antipsychotic medications causes both weight gain and an increase in leptin levels (13). In addition, multiple lines of evidence point toward a role for leptin in the immune system. In rat and mouse models, leptin has been shown to reduce the threshold for pain (14). Leptin has also been shown to increase levels of interleukin-1, a cytokine known to cause hyperalgesia (15). Leptin

${ }^{1}$ Department of Rheumatology, Tel Aviv Sourasky Medical Center; ${ }^{2}$ Internal Medicine, Tel Aviv Sourasky Medical Center, Tel Aviv; ${ }^{3}$ Institute of

Endocrinology Metabolism and Diabetes, Rabin Medical Center, Petach - Tikvah; ${ }^{4}$ The Institute of Endocrinology, Sheba Medical Center, Tel-

Hashomer; Sackler School of Medicine, Tel Aviv University, Tel Aviv, Israel

Correspondence: Dr Jacob N Ablin, Department of Rheumatology, Tel Aviv Sourasky Medical Center, Weizman Street 6, Tel Aviv 64239, Israel.

Telephone 972-3-6973668, fax 972-3-6974577, e-mail ajacob@post.tau.ac.il 
TABLE 1

Basic demographic data of patients and controls

\begin{tabular}{llll}
\hline & Group & $\mathbf{n}$ & Mean \pm SD \\
\hline Age, years & Control & 21 & $40.48 \pm 9.68$ \\
& Patient & 16 & $50.44 \pm 9.61$ \\
Body mass index, $\mathrm{kg} / \mathrm{m}^{2}$ & Control & 21 & $26.55 \pm 5.66$ \\
& Patients & 16 & $25.55 \pm 4.55$ \\
\hline
\end{tabular}

increases the rate of metabolism of serotonin, an important transmitter in pain processing (16), while treatment with citalopram, a selective serotonin reuptake inhibitor (SSRI), causes a decrease in leptin levels (17).

In view of this background, and particularly in light of the roles and interactions between leptin and the immune system, the HPA system as well as the effect on pain threshold, the present study aimed to evaluate the possibility of an alteration in levels of leptin patients suffering from fibromyalgia, a prototypical disorder of central pain processing.

\section{METHODS}

Sixteen female fibromyalgia patients were recruited from the fibromyalgia clinic at the Tel Aviv Sourasky Medical Center Rheumatology Institute (Tel Aviv, Israel). The patients underwent clinical evaluation that included manual dolorimetry, tender point evaluation and count. Weight and height were documented, and body mass index (BMI) was calculated. Demographic details and medical history were documented. Fulfilment of 1990 American College of Rheumatology classification criteria of fibromyalgia was documented (18). Written informed consent was obtained from all patients and the study protocol was approved by the institutional Helsinki committee.

Plasma samples were obtained on recruitment for leptin determination. Twenty-one healthy female individuals were recruited as the control group. Patients receiving long-term medical treatment for fibromyalgia (eg, SSRIs) were excluded, as well as patients treated during the preceding four weeks. The use of short-term analgesics such as acetaminophen was permitted.

\section{Quality of life evaluation}

The following questionnaires were used for evaluation of quality of life and impact of fibromyalgia on the patients:

- The Short-Form-36 Health Survey (SF-36), a 36-item questionnaire assessing various aspects of quality of life, including physical and mental components. This tool has been previously tested and validated for measuring quality of life in patients with fibromyalgia (19)

- Based on the response to these questions, the Mental Component Summary (MCS) and the Physical Component Summary (PCS) were calculated (20).

- The Fibromyalgia Impact Questionnaire (FIQ), which expresses the effect the fibromyalgia syndrome (FMS) has on the patient's quality of life, based on the reported severity of symptoms (reported on a visual analogue scale); parameters such as fatigue, depression, anxiety and pain are included. In the current study, a validated translation of the Hebrew version of the FIQ was used (21).

- The depression and anxiety questionnaires taken from the Arthritis Impact Measurement Scale (AIMS) scale were also used (22).

On recruitment, all patients received general explanations on the nature of their medical problem and were instructed about the value of physical activity in fibromyalgia. The use of medications for the treatment of fibromyalgia such as tricyclic compounds or SSRIs was left to the discretion of the attending rheumatologist on clinical grounds.

Three months after recruitment, patients were invited for a second interview in the course of which a physical examination was performed, including dolorimetry, and a second blood sample was obtained for determination of leptin levels. Control individuals did not undergo a repeat examination.
TABLE 2

Levels of leptin measured among patients and controls, before and after three months of treatment

\begin{tabular}{lcccc}
\hline Group & $\mathbf{n}$ & Leptin $\mathbf{0}^{*}$ & $\mathbf{n}$ & Leptin 2 $^{\dagger}$ \\
\hline Control & 21 & $15.96 \pm 8.90$ & 21 & - \\
Patients & 16 & $15.74 \pm 7.30$ & 13 & $18.10 \pm 7.84$ \\
\hline
\end{tabular}

${ }^{*}$ Leptin 0 Leptin levels (mean $\left.\pm \mathrm{SD}\right)$ at recruitment $(\mathrm{ng} / \mathrm{mL}) ;{ }^{\dagger}$ Leptin 2 Leptin levels (mean $\pm S D$ ) after three months of treatment $(\mathrm{ng} / \mathrm{mL})$

Determination of leptin levels

Samples of venous blood were drawn between 08:00 and 09:00 into test tubes containing EDTA. Samples underwent centrifugation and plasma was kept at $-20^{\circ} \mathrm{C}$ until processing. Levels of leptin were determined by the use of a commercial ELISA kit (Linco Research Incorporation, USA). The test's sensitivity was $0.5 \mathrm{ng} / \mathrm{mL}$ and the interassay coefficient of variation was in the range of $3 \%$ to $6 \%$.

\section{Statistical analysis}

Comparison of the two study groups (fibromyalgia patients and controls) regarding clinical and demographic data at outcome was performed with the use of the $t$ test for independent samples. Comparison between the patients regarding leptin levels before and after three months of treatment was performed using ANOVA after adjustment for BMI.

In the patient group, the relationship between baseline leptin levels and change in leptin levels, as well as the relationship with demographic and clinical parameters, was performed using the Pearson correlation.

Statistical analysis was performed using SPSS version 13.0 (IBM Corporation, USA) for Windows (Microsoft Corporation, USA), and the level of statistical significance was set at 0.05 .

\section{RESULTS}

Sixteen patients fulfilling American College of Rheumatology criteria for classification of fibromyalgia were recruited, as were 21 healthy controls. All individuals recruited were females. Thirteen patients returned for a second examination. Basic demographic data regarding the patients and controls are summarized in Table 1 .

The fibromyalgia patients recruited were treated at the discretion of the attending physician. All patients were instructed about the benefits of physical activity in the treatment of fibromyalgia and about the importance of good sleep hygiene. In addition, patients were treated with medications that included tricyclic antidepressants (eg, amitriptyline), SSRIs and serotonin/noradrenaline reuptake inhibitors (SNRIs). Table 2 summarizes the levels of leptin measured among fibromyalgia patients and controls, including results obtained after three months of treatment. As presented in Table 2, no significant difference was observed between leptin levels between patients and controls.

To take into consideration the effect of BMI on levels of leptin, a calculation was performed based on one-way ANOVA with covariance. No significant change was observed between the groups after adjustment for BMI.

To evaluate the effect of medical treatment on leptin levels, results were analyzed after dividing the patients into subgroups of those treated and those not treated with medications. No significant change was observed between the treated and untreated groups, including after BMI adjustment.

To evaluate the relationship between leptin levels and clinical parameters of the patients over the three-month period, Pearson correlation was computed between the leptin levels at time of recruitment and the parameters, which included the MCS, PCS, AIMS, FIQ, point count and level of sensitivity. No correlation was found between leptin levels at recruitment and any of the clinical parameters evaluated.

In addition, the relationship between the change in leptin levels over the three months of treatment and the changes in the clinical 
parameters was evaluated. The results showed no statistically significant correlation between these parameters.

Notably, no significant improvement was observed in the clinical parameters of fibromyalgia patients evaluated, based on FIQ and SF-36 parameters (MCS and PCS).

\section{DISCUSSION}

The present study attempted to evaluate the relationship between fibromyalgia and serum levels of leptin. The results do not support the existence of a significant difference in serum levels of leptin between fibromyalgia patients and healthy controls. In addition, no significant change was observed in leptin levels before and after three months of standard treatment for fibromyalgia. As described in the introduction, leptin has a significant role in the regulation of the stress response, including the response of the HPA axis to stress $(23,24)$ as well as in pain regulation (25), while a counterbalance has been described between levels of leptin and levels of cortisol in fibromyalgia (26). In view of this background, an association between serum leptin levels and fibromyalgia per se or fibromyalgia severity appeared plausible. The lack of evidence of such a relationship in the current study may be attributed to several factors. The small size of the study sample may have limited our capability to identify a small effect. The heterogeneity in the treatment received, as well as the short period of follow-up, may similarly have limited our capacity to identify the effect of treatment on the leptin levels. Also, the lack of a significant clinical effect in the present study is an obvious limitation. This finding may reflect the difficulty in achieving significant improvement in FMS patients, as well as the inconsistent implementation of recommended and evidencebased treatment modalities. The lack of a change in leptin levels during the period of the study is also not surprising, considering the lack of a significant difference at baseline between patients and controls.

Nonetheless, we consider the comparison between fibromyalgia patients and controls to be the more significant finding of our study, which was not powered to evaluate a response to treatment. It is also noteworthy that, in the present study, no intervention was conducted regarding the treatment strategy of the patients, who were managed by the attending physicians according to clinical discretion. The fact that most patients were treated with SSRIs (rather than with more evidencebased treatments such as pregabalin and SNRIs) may point to insufficient awareness regarding optimal management of the FMS. In addition, it may reflect difficulties with insurance coverage because no medications have, to date, been introduced into national health insurance coverage in Israel for the fibromyalgia indication.

The possibility also exists that additional factors apart from leptin, which participate in the regulation of the metabolic rate, may play a more complex role in the pathogenesis of fibromyalgia. Thus, mediators such as ghrelin and neuropeptide-Y (27) have been shown to play a role in the pathogenesis of fibromyalgia and in the body's response to stress (28). Thus, it may be that the interaction among several metabolic mediators is more significant than the level of one particular player, as assessed in the present study.

Regarding the apparent lack of effect of treatment on leptin levels in the present study, it must be pointed out that various studies have previously demonstrated an effect of medications such as SSRIs $(28,30)$, often prescribed for fibromyalgia patients, on leptin levels as well as an association between leptin levels and depression (31). In the present study, five of 16 patients were treated with an SSRI or an SNRI. No significant change was discerned regarding the AIMS and MCS parameters, expressing levels of anxiety and depression. Concurrently, no change was observed in leptin levels. Thus, it is possible that the observed lack of effect on leptin levels is the result of the relatively small sample size and short duration of treatment that precluded a more profound effect of SSRI/SNRI treatment.

Our results contrast with those previously reported by Fietta and Fietta (26), as noted above, who reported in a small study the finding of a counterbalance between leptin and cortisol in FMS patients. The authors of that study raised the possibility that leptin may play a role in maintaining a state of hypervigilance in FMS, similar to the posttraumatic state. Notably, all patients in their study were reported to be untreated and, thus, it is possible that the effects of treatment may have masked a difference in our study.

Leptin levels are influenced by BMI; in the present study, as in the study by Fietta and Fietta (26), nonobese patients were recruited, patients and controls were matched for BMI and comparisons of leptin levels were adjusted for BMI.

Another possible confounder relates to the effect of the menstrual cycle on leptin levels. Leptin levels are known to peak during the luteal phase compared with the follicular phase (32). Thus, comparing patients who were synchronized regarding the menstrual cycle, as well as excluding menopausal patients, may have improved accuracy and enhanced the chance of identifying small differences in leptin levels.

\section{CONCLUSION}

The results of the present study do not support the existence of a significant difference in leptin levels between fibromyalgia patients and healthy controls.

\section{REFERENCES}

1. Dadabhoy D, Clauw DJ. Therapy Insight: Fibromyalgia - a different type of pain needing a different type of treatment. Nat Clin Pract Rheumatol 2006;2:364-72.

2. Clauw DJ, Crofford LJ. Chronic widespread pain and fibromyalgia: What we know, and what we need to know. Best Pract Res Clin Rheumatol 2003;17:685-701.

3. Adler GK, Kinsley BT, Hurwitz S, Mossey CJ, Goldenberg DL. Reduced hypothalamic-pituitary and sympathoadrenal responses to hypoglycemia in women with fibromyalgia syndrome. Am J Med 1999;106:534-43.

4. Jones KD, Deodhar P, Lorentzen A, Bennett RM, Deodhar AA. Growth hormone perturbations in fibromyalgia: A review. Semin Arthritis Rheum 2007;36:357-79.

5. Hudson JI, Goldenberg DL, Pope HGJ, Keck PEJ, Schlesinger L. Comorbidity of fibromyalgia with medical and psychiatric disorders. Am J Med 1992;92:363-7.

6. Zhang Y, Proenca R, Maffei M, Barone M, Leopold L, Friedman JM. Positional cloning of the mouse obese gene and its human homologue. Nature 1994;372:425-32.

7. Ruhl CE, Everhart JE. Epidemiology of nonalcoholic fatty liver. Clin Liver Dis 2004;8:501-19.

8. Gordon ME, McKeever KH. Diurnal variation of ghrelin, leptin, and adiponectin in standard-bred mares. J Anim Sci 2005;83:2365-71.

9. Heiman ML, Ahima RS, Craft LS, Schoner B, Stephens TW, Flier JS. Leptin inhibition of the hypothalamic-pituitary-adrenal axis in response to stress. Endocrinology 1997;138:3859-63.

10. Kain ZN, Zimolo Z, Heninger G. Leptin and the perioperative neuroendocrinological stress response. J Clin Endocrinol Metab 1999;84:2438-42.

11. Gaillard RC, Spinedi E, Chautard T, Pralong FP. Cytokines, leptin, and the hypothalamo-pituitary-adrenal axis. Ann N Y Acad Sci 2000;917:647-57.

12. Kraus T, Haack M, Schuld A, Hinze-Selch D, Pollmächer T. Low leptin levels but normal body mass indices in patients with depression or schizophrenia. Neuroendocrinology 2001;73:243-7.

13. Lean ME, Pajonk FG. Patients on atypical antipsychotic drugs: Another high-risk group for type 2 diabetes. Diabetes Care 2003;26:1597-605.

14. Kutlu S, Canpolat S, Sandal S, Ozcan M, Sarsilmaz M, Kelestimur H. Effects of central and peripheral administration of leptin on pain threshold in rats and mice. Neuro Endocrinol Lett 2003;24:193-6.

15. Hosoi T, Okuma Y, Nomura Y. Leptin regulates interleukin-1beta expression in the brain via the STAT3-independent mechanisms. Brain Res Molec Brain Res 2002;13:139-46.

16. Calapai G, Corica F, Corsonello A, et al. Leptin increases serotonin turnover by inhibition of brain nitric oxide synthesis. J Clin Invest 1999;104:975-82.

17. Atmaca M, Kuloglu M, Tezcan E, Ustundag B, Semercioz A. Serum leptin levels in patients with premature ejaculation before and after citalopram treatment. BJU Int 2003;91:252-4. 
18. Wolfe F, Smythe HA, Yunus MB, et al. The American College of Rheumatology 1990 Criteria for the Classification of Fibromyalgia. Report of the Multicenter Criteria Committee. Arthritis Rheum 1990;33:160-72.

19. Neumann L, Berzak A, Buskila D. Measuring health status in Israeli patients with fibromyalgia syndrome and widespread pain and healthy individuals: Utility of the short form 36-item health survey (SF-36). Semin Arthritis Rheum 2000;29:400-8.

20. Ware JE, Kosinski M, Keller SK. SF-36 ${ }^{\circledR}$ Physical and Mental Health Summary Scales: A User's Manual. Boston: The Health Institute; 1994.

21. Buskila D, Neumann L. Assessing functional disability and health status of women with fibromyalgia: Validation of a Hebrew version of the Fibromyalgia Impact Questionnaire. J Rheumatol 1996;23:903-6.

22. Meenan RF, Gertman PM, Mason JH. Measuring health status in arthritis. The arthritis impact measurement scales. Arthritis Rheum 1980;23:146-52.

23. Heiman ML, Ahima RS, Craft LS, Schoner B, Stephens TW, Flier JS. Leptin inhibition of the hypothalamic-pituitary-adrenal axis in response to stress. Endocrinology 1997;138:3859-63.

24. Kain ZN, Zimolo Z, Heninger G. Leptin and the perioperative neuroendocrinological stress response. Clin Endocrinol Metab $1999 ; 84: 2438-42$.
25. Kutlu S, Canpolat S, Sandal S, Ozcan M, Sarsilmaz M, Kelestimur H. Effects of central and peripheral administration of leptin on pain threshold in rats and mice. Neuroendocrinol Lett 2003;24:193-6.

26. Fietta P, Fietta P. Counterbalance between leptin and cortisol may be associated with fibromyalgia. Psychiatry Clin Neurosci 2006;60:529.

27. Anderberg UM, Liu Z, Berglund L, Nyberg F. Elevated plasma levels of neuropeptide $\mathrm{Y}$ in female fibromyalgia patients. Eur J Pain 1999;3:19-30.

28. Tander B, Atmaca A, Aliyazicioglu Y, Canturk F. Serum ghrelin levels but not GH, IGF-1 and IGFBP-3 levels are altered in patients with fibromyalgia syndrome. Joint Bone Spine 2007;74:477-81.

29. Atmaca M, Kuloglu M, Tezcan E, Ustundag B, Semercioz A. Serum leptin levels in patients with premature ejaculation before and after citalopram treatment. BJU Int 2003;91:253-4.

30. Moosa MY, Panz VR, Jeenah FY, Joffe BI. African women with depression: The effect of imipramine and fluoxetine on body mass index and leptin secretion. J Clin Psychopharmacol 2003;23:549-52.

31. Eikelis N, Esler M, Barton D, Dawood T, Wiesner G, Lambert G. Reduced brain leptin in patients with major depressive disorder and in suicide victims. Mol Psychiatry 2006;11:800-1.

32. Ludwig M, Klein HH, Diedrich K, Ortmann O. Serum leptin concentrations throughout the menstrual cycle. Arch Gynecol Obstet 2000;263:99-101. 


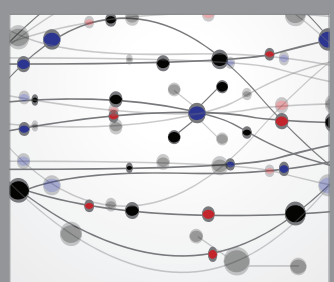

The Scientific World Journal
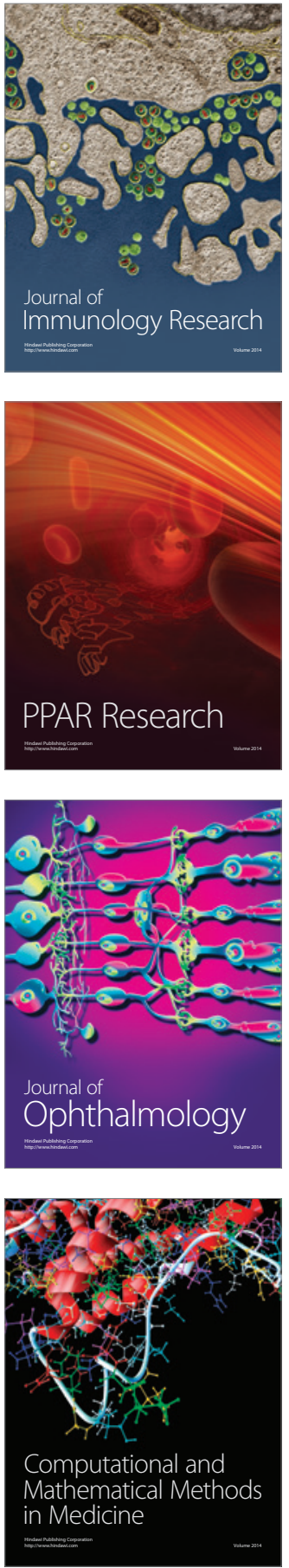

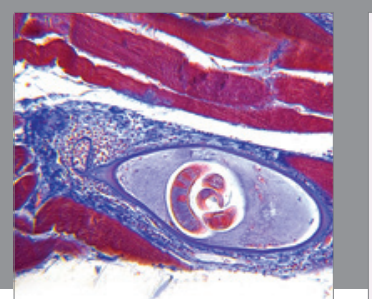

Gastroenterology Research and Practice

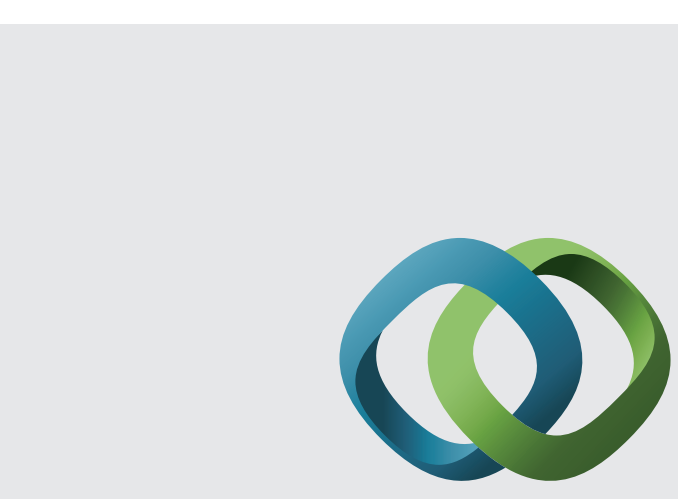

\section{Hindawi}

Submit your manuscripts at

http://www.hindawi.com
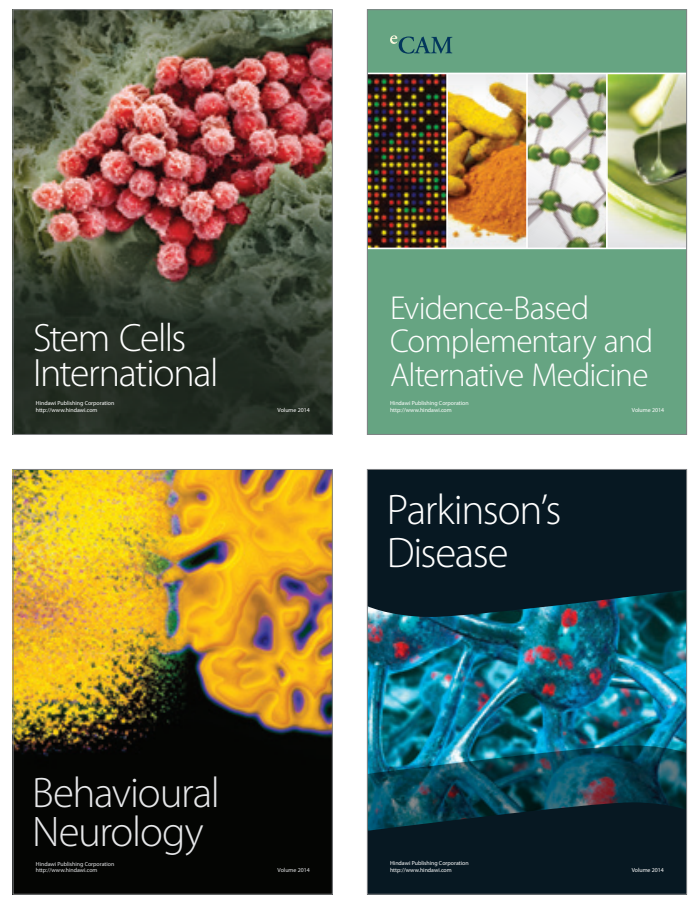
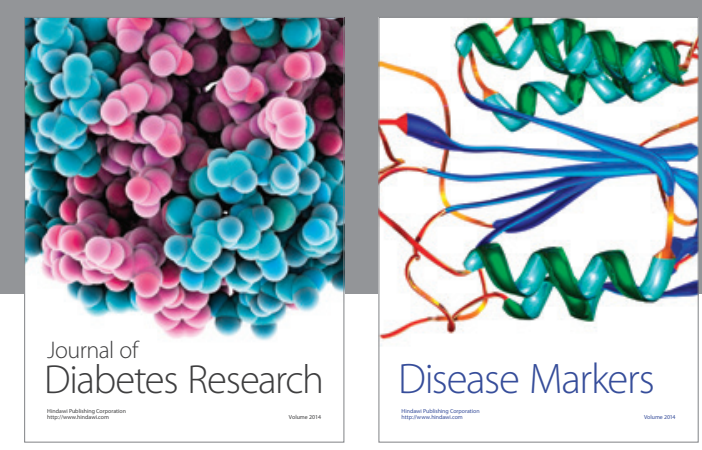

Disease Markers
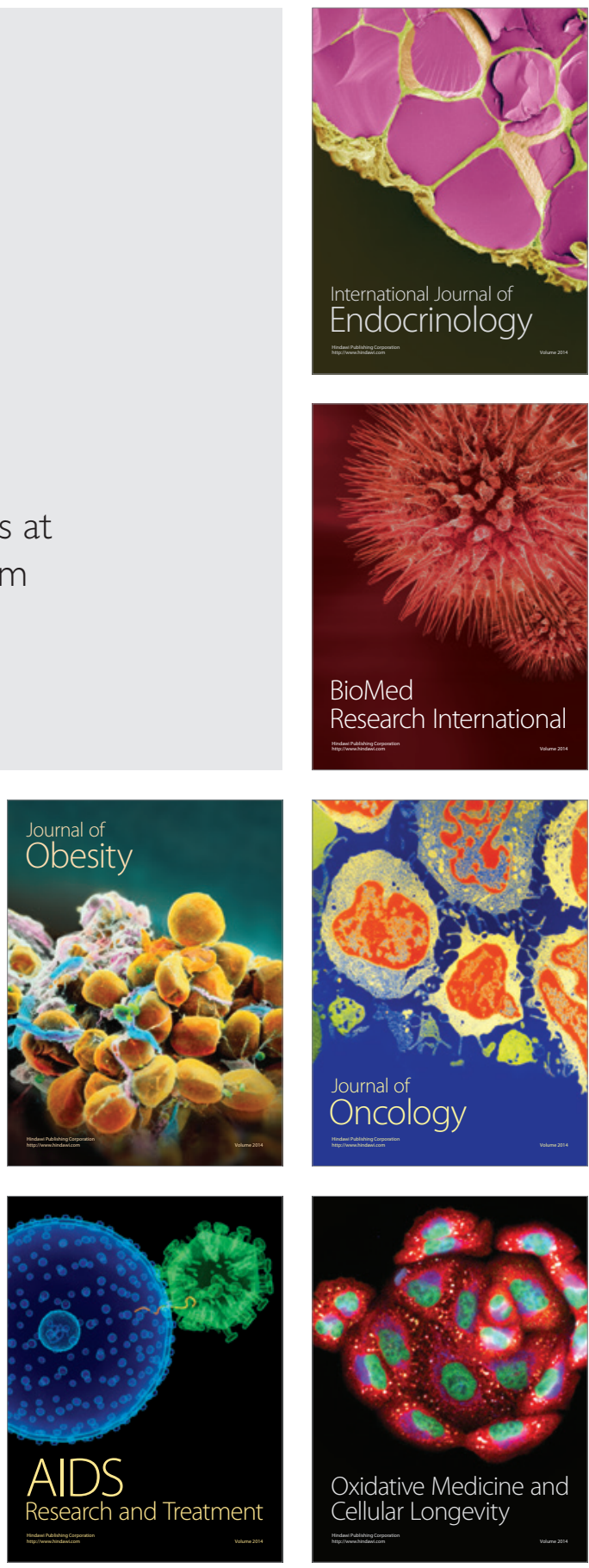